may be even more potent than it is reckoned. With associations growing in influence, and the great facilities afforded for exchange of ideas, the body of teachers is very rapidly increasing in strength, and this reform in the teaching of mathematics, together with many another much-needed reform, is perhaps much more in the immediate future than is thought. At any rate, if the bow and arrow is still the official weapon, the use of the magazine rifle is being secretly taught, and we school teachers look forward with no misgivings to that great fight. Prof. Perry sees ahead for our people, rather we are "spoiling for it," for with it will come our freedom !

I Macdonald Place, Hartlepool, March 29. FRANK L. WARD.

\section{Rearrangement of Euclid Book I., Pt. i.}

IN answer to Prof. Lodge's letter I should like to say that we have for some time followed much the order he suggests. Euclid's order unnaturally separates propositions which should come together, e.g. I. 4, 8, 26, and is, therefore, a serious hindrance to a clear grasp of the subject-matter as distinct from mere exercise in logic.

The following order-substantially that suggested by Prof. Lodge-seems natural, and we have certainly found it work very well in practice.

(I) The propositions on angles, viz. 13, 14, I5, 27, 29, 32, cor. 2, 32. At this stage logical deduction from definitions and axioms is difficult and, to a boy, unconvincing. The following proof of I. 32 cor. 2 is convincing, at least : "If a man walks right round a rectilineal figure (starting and ending at a point in the middle of a side), he turns once round. Hence the exterior angles, which are the angles through which he turns, are together equal to 4 right angles." Similar proofs of 27 and 29 are equally convincing. Any attempt to analyse these proofs into the axioms on which they depend seems to me at this stage foolish ; it is work for a highly trained and speculative mind, not for a boy.

(2) Triangulation, 1. 4, 8, 26

These are, I think, best presented as the outcome of experience passing into intuition, and as special cases of the general fact that three data are necessary and sometimes sufficient to determine a triangle. The special case of right-angled triangles with hypotenuse and one side given should be added and proved deductively from $\mathrm{I}$. 5 .

The rest of Book I. consists of exercises on these fundamental propositions :-Properties of a single triangle, I. $20,5,18,6$, 19; loci; quadrilaterals; areas. The order in which these last three subjects are taken is immaterial.

A special advantage of this arrangement is that it makes it easy to combine practical with theoretical work. It was, indeed, from the attempt to do this that we were led to follow this order, but even in purely theoretical work it has proved a great gain.

As to the omission of "constructions" from the deductive course, we agree-they are properly treated as exercises.

As to the effect of this change on real progress we have no doubt. As to examinations, we hope that they will before long (1) permit freedom in the order of propositions, (2) diminish bookwork and insist upon riders and practical work, as some, indeed, already do.

It seems illogical, but even in deserting Euclid's order we adhere to his numbers. The constant reference to cardinal propositions is a great help to thoroughness and clearness of knowledge, as well as to ease of questioning and answering. Probably no one will ever succeed in fixing fresh labels on to the propositions, and for the present at least we find the old ones useful, though they are to our boys quite arbitrary.

\section{Liverpool Institute.}

W. C. FI.ETCHER.

I Quite agree with Prof. Alfred Lodge as to the order of propositions he proposes, which is practically the order I adopted in my "Foundations of Geometry." But he does not in his letter refer to what seems to me the chief reason for it, which is that the elementary geometry of straight lines and angies should precede the geometry of plane surfaces, including any propositions about areas. And to carry out this idea, the fundamental propositions which Euclid gives so badly in his XIth. book (props. $1-9$ ) ought to be taken hefore such propositions as his I. 35 and 36 . On the other hand, there are important proNO. I 694, voL. 65 ] positions in the XIth. book, notably prop. Io (if this is not included in the definition of parallelism) and props. 20 and $2 \mathbf{I}$, which come properly in what Prof. Lodge calls the first part of Book I.

By the way, I may mention that it seems to me illogical to prove I. 27 , as Prof. Lodge does, by a simple "which is impossible," and to refer I. 29 to "Playfair's axiom." Neither proposition is nearer a priori truth than the other, and it is just as easy to disguise the difficulty, if you wish to do so, in either case.

Racketts, Hythe, Hants, April I 4. EDWARD T. DIXON.

WE have had the following arrangement of Euc., $1-32$, in use for three years with more than two hundred pupils. I3, I4 (from the definitions); $15 ; 32$, cor. $2,32,16,17 ; 23,8,9$ 4 , Io. Locus of a point equidistant from two given points. II, 12 $5 ; 26,6$. Locus of points equidistant from two intersecting straight lines.

This gives fourteen propositions ; thirty-seven more complete all the plane geometry of Euc. I.-VI. and XII. required in mathematics or science. We have no superposition "proofs"; they merely obscure obvious truths. Parallels by superposition have been found beyond the capabilities of beginners. Why not alter the definition? At present it gives the least obvious property of parallels.

A caution to the professors who are teaching us how to teach. We are seeking a system of geometry suitable for boys of ten, and the most logical method is not necessarily the best; it is better to separate $4,8,26$ by examples of their use and to leave the remaining case for trigonometry. Again, an ideal course must be inventional, and must grow out of practical work; therefore it must introduce problems as early as possible: a beginner should not be allowed to quote a construction which he cannot perform. Is not the demand for a purely theoretical course due to a desire to use $I, 9$, in proving $I, 5$, whilst retaining Euclid's proof of $\mathrm{x}, 8$ ?

Leyton Technical Institute, April 14.

IN reply to the appeal of Prof. Alfred Lodge for opinions with reference to his proposal to alter the sequence of Euclid's propositions by introducing those relating to parallels at the earliest possible stage, permit me to express what I hold to be insuperable objections to his proposed innovation.

Whatever other objections may be raised to Euclid's sequence of propositions, it at any rate has this distinguishing merit, that it separates the propositions (I. I-28) which are independent of the postulate of parallels from those which are true only when that postulate is admitted. To obscure this distinction, as, for instance, by treating props. 16,17 as corollaries of prop. 32 and so appearing to depend on the postulate of parallels, would to my mind, especially now that the non-Euclidean geometry of Lobatchewsky and others is an established part of mathematical science, be a distinctly retrograde step.

Further, this innovation is not in the least necessary to secure Prof. Lodge's object (with which I entirely sympathise), namely, a better and more natural grouping of the propositions about triangles.

For this purpose all that is necessary is to add I, I6 to the three (13, 14, I5) with which he proposes to begin. This proposition may at once be proved as follows :-

The triangle being $\mathrm{A} \mathrm{BC}$, the side $\mathrm{B} C$ produced to $\mathrm{D}$ and $\mathrm{E}$ the mid-point of $\mathrm{AC}$, turn the triangle $\mathrm{AE} B$ about Euntil $\mathrm{E} A$ comes on $\mathrm{EC}$ and $\mathrm{A}$ on $\mathrm{C}$, then $\mathrm{E} \mathrm{B}$ comes to a position $\mathrm{EF}$ in the same straight line as $\mathrm{BE}$, and since $\mathrm{BEF}, \mathrm{BCD}$ meet in $B$. they cannot meet again, so that $F$ lies on the same side of $\mathrm{BD}$ as $\mathrm{A}[\mathrm{N} . \mathrm{B}$., here comes in the difference between plane and spherical surface geometry], and ECF or the angle $\mathrm{A}$ is less than the exterior angle A C D.

This proved and I. I 7 as its corollary, the propositions about a single triangle and those about the comparison of triangles easily fall into a simple and natural sequence and grouping. Shanklin, April I 2. ROBT. B. HAYWARD.

\section{Winter Phenomena in Lakeland.}

THERE being no record within my knowledge as to whether holly and ivy are starch-trees or fat-trees, i.e. as to whether their wood-starch disappears or otherwise in winter, a strict watch was set upon the phenomena. During the months of December, January and February, sections were taken at 